\title{
Number of Days from Date of Initial Cancer Diagnosis to Date of Last Contact
}

National Cancer Institute

\section{Source}

National Cancer Institute. Number of Days from Date of Initial Cancer Diagnosis to Date

of Last Contact. NCI Thesaurus. Code C156918.

The number of days from the date of initial cancer diagnosis to the date of last contact. 